\title{
Corpus-Based Move Analysis of TED Talks about Education
}

\author{
Xuwei Li, Feipeng Li \\ Baoding University, Baoding, China \\ Email: weiwei840311@163.com
}

How to cite this paper: Li, X. W., \& Li, F. P. (2021). Corpus-Based Move Analysis of TED Talks about Education. Creative Education, 12, 166-175.

https://doi.org/10.4236/ce.2021.121012

Received: December 31, 2020

Accepted: January 19, 2021

Published: January 22, 2021

Copyright $\odot 2021$ by author(s) and Scientific Research Publishing Inc. This work is licensed under the Creative Commons Attribution International License (CC BY 4.0).

http://creativecommons.org/licenses/by/4.0/

\begin{abstract}
This present paper explores the rhetorical structure of some selected talks from TED conference under the topic of education to discuss the essential and optional moves applied in these talks. Based on the result the author tries to talk about the possibility of incorporating such instruction of oral presentation in academic genre in college English classroom. The study sets up a corpus of TED talks with the tag of education to tease out the shared structure features and flexibility in them. The study identifies the essential and optional moves based on the frequency and occurrence. Meanwhile, the findings also indicate the importance of topic and conventions of TED conferences.
\end{abstract}

\section{Keywords}

Corpus-Based Research, Move Analysis, Oral Presentations in Academic Genre, TED Talk

\section{Introduction}

Oral presentation skills are regarded as one of the most important communication skills. For college English learners, oral skills are also important in both academic genre and workplace. Presentation skills lie in the central place of English learners' professional success in the academic genre (Evans, 2013). More and more universities included presentation skills in the curriculum aiming to facilitate students' acquisition of the language. Coursebooks of public speaking or oral presentation skills usually focus on introduce prescriptive rules and samples invented by the writers. Teachers of such course tend to collect authentic video, audio materials to supplement the printed textbook, but the examples they can find most are the inaugural speech or parliament presentation, these context-specific speeches are not very suitable to serve the pedagogical purpose in English classroom. In countries like China, English is mainly taught and used in 
the context of classroom and in the academic genre, so the instruction of oral presentation skills should be specified. With the previous discussion in mind teachers of public speaking and oral presentation courses in universities often face the problem of lack of appropriate pedagogical materials to help their instruction.

Nowadays many researches have revealed the difference between spoken and written discourse in academic genre in terms of interactive strategies (Biber, Conrad, Reppen, Byrd, \& Helt, 2002). Many other studies reported the importance of guiding the students to prepare and deliver oral presentations (Bunch, 2009; Chou, 2011). There are abundant literatures on the topic of how to coach and develop materials for classroom teaching (De Grez, Valcke, \& Roozen, 2009; Evans, 2013).

Many researchers recommended that TED talks are a beneficial resource for improving students' English presentation skills in the academic genre. TED is a nonprofit organization devoted to convey ideas cross discipline and culture. Many experts in different professional fields are invited to present their ideas in TED conference, in order to share and inspire the public in thoughtful short talks. These innovative outstanding discipline-specific presentations provide us with substantial materials of learning academic presentations. The purpose and popularity of TED talks make them one of the most accessible and appropriate resources for oral presentation instructions. TED talks are not only considered beneficial in English listening teaching (Takaesu, 2013), but also used to motivate students' critical thinking and classroom discussion (DaVia Rubenstein, 2012). Besides the previous studies, there are few studies discuss the rhetorical and communicative structures of TED talks which are very useful in training academic presentation skills. This study tends to conduct a corpus-based move analysis in the specific genre of education in TED talks aiming to investigate the general pattern of rhetorical structure in this discipline and shed some light upon the pedagogical puritanical of using TED talks in the instruction of oral presentation skills in the academic genre.

\section{Literature Review}

\section{Move analysis of spoken discourse}

In 1990 Swales first coined the rational of move analysis, it is a method used to analyze rhetorical features in a genre. Swales defined move as a part of text serve specific purpose and meanwhile devote to the overall communicative success in genre. Each move can be furtherly subcategorized into different steps which support the purpose of move (Connor, Upton, \& Kanoksilapatham, 2007). The aim of move analysis is to identify how do the moves and steps are organized to develop a coherent and comprehensible discourse (Tardy, 2011). Swales (1990), provided a framework for move analysis in written genre which include three types of move namely: "establishing a territory, establishing a niche, and occupying a niche/presenting the presents work" (Chang \& Huang, 2015: p. 32). Move analysis was firstly developed to address the genre patterns in written texts. Swales 2004 began to applied move analysis to spoken genre. Prior to Swales 
himself many other scholars had conducted studies about move analysis in spoken discourse. Thompson (1994) researched the introduction part of 18 academic lectures and identified two essential types of moves in it. More importantly she argued that the inconsistent use of moves and steps cross genre make it difficult to distinguish the function of every type of move from each other.

Approach of corpus-based move analysis

Move analysis is considered as a top-down process of discourse analysis which focuses on analyzing the higher-level rhetorical structure of text to identify the general pattern of how the arrange the text. With the development of corpus linguistics studies used corpus provided more evidence to show the necessity of combining bottom-up approach into structure analysis, both qualitative and quantitative analysis offered beneficial materials for classroom teaching.

Biber and his colleagues (2007) developed a corpus-based move analysis framework and discussed the electronic coding methods of doing such research. In the framework Biber and his team emphasized the importance of identifying the move types in spoken discourse using a well-designed coding system as well as how to evaluate the inter-rater reliability during the coding process. Quantitative analysis should be done soon after the coding process finished, by counting the frequency of move types some general structure patterns could be seen. A move analysis study of birthmother letters (Upton \& Cohen, 2009) illustrates that corpus-based method facilitate the researchers to analysis a large number of texts which may reveal more salient features than ever before.

TED talks move analysis based on Corpus

As a newly developed research genre only a few studies included corpus approach in the move analysis of TED talks. Chang and Huang (2015) developed a corpus of TED talks contained about 960 texts after identification and evaluation they chose 58 presentations across disciplines. With a careful analysis the authors finally summarized a typical move structure in TED talks, take frequency into consideration, topic introduction is the only obligatory move in the introduction part, topic development in the boy part commonly occurred in most presentations, and the conclusion part which is the shortest but seemed to have more stable structure with three essential types of move namely: acknowledgements/gratitude, closure, and concluding messages. At the end of the paper the authors argued that the selected texts cross different disciplines maybe one reason for a less salient pattern in the findings, the lake of in-depth view in one discipline left room for future move analysis in TED talks. According to the suggestion form Chang and Huang the current study plan to analyze the move structure in TED education talks, identify the essential rhetorical structure in this specific genre, and discuss the pedagogical potential of TED talks in oral presentation skills instruction.

\section{Methodology}

\section{1) Selection of the corpus}

The corpus used in this research includes 12 TED education talks selected 
from the TED website. The collection of the texts is based on the construct of achieving representativeness of the oral presentations under the topic of education. Aiming to ensure the selected talks shared the genre specific characteristics according to the discipline of education, the selection was made based on several criteria:

a) There are 148 talks under the tag of education and the length of which varied from 3 to 27 minutes, the author chose 3 talks according to the duration categories provided by TED website namely: $0-6$ mins; $6-12$ mins; $12-18$ mins; and 18+ mins. And 12 talks in total, the name, length, and link of the 12 talks can be viewed in the appendix.

b) For this study aimed to explore the pedagogical use TED talks and move analysis in facilitating students' English oral presentation learning, all the selected talks should be presented in English. Selection was restricted to talks delivered by single presenter.

c) Presentations which contained other forms of onstage performance like dances, poetry, new media technology display, and music were excluded from the corpus for the purpose of analyzing the move in monologues.

d) The final decision of the 12 talks was made based on list of viewing rate, for most reviewed talks indicated the audience's preference and that is one of the predictor of the quality of a TED talk. High quality talks should be outstanding both in strategy use as well as content and should be more representative for the move features in this discipline. The top three most viewed talks in different duration section were selected and when the talks violated previous criteria the flowing talk would be viewed and included when met the criteria.

Finally, 12 TED talks with a total number of 24,267 words were collected for further analysis. The average length of the 12 talks is 2022 words.

\section{Coding protocol}

After developing the TED talks corpus in this study, the author began to identify the functional components in the talks according to the purpose of segments. From the introduction in TED website, TED talks aim to spread the innovative ideas to worldwide audience. A general picture can be drawn from the instruction is that the invited speakers in TED conference are experts or practitioners from various academic disciplines try to convey their ideas to common and ordinal audience, in order to serve this purpose presenter may use different move structures in their talks according to many reasons. Based on the coding catteries used by Chang and Huang (2015), the author began to watch the TED talk videos and check the transcripts provided by TED website. After a draft move analysis of two randomly selected talks from TED talks about education, the author made possible adjustment to the coding system by providing new explanations and examples to some steps in the system. One of the author's course mates was invited to code another two randomly selected TED talks in education using the same coding system, negotiation and agreement were made after the second analysis to establish a set of suitable coding criteria for current corpus. 
In order to achieve the validity and reliability of the coding procedure the author trained another coder to help with the manually coding task. the coder was received explicit training about the coding criteria and practice coding with TED talks. Two coders code one randomly selected talk and the inter-coder agreement examined by MAXQDA is $84 \%$ indicates that the coding criteria are reliable and the classification of moves and steps are clear (see Table 1). The result will be reported in the result section.

\section{Result}

\section{1) Basic description of the 12 TED talks}

Firstly, the author identified the introduction, body, and conclusion part of the 12 presentations. From the data in Table 2, body part occupied the largest proportion in the talks, followed by with the conclusion and introduction parts. The body part also shows the greatest standard deviation among the three components of a talk and the introduction and conclusion have similar SD in this corpus. The SD values suggest that although the full length of these 12 talks is various, the presenters devoted similar amount of words in the beginning and ending part of the presentation.

\section{2) Essential moves in TED talks}

The purpose of this study is to find out the distribution of obligatory moves in different parts of TED talks in the topic of education. In the 12 selected talks the

Table 1. Correlation rate.

\begin{tabular}{ccccc}
\hline Code & Correlates & Doesn't correlate & Total & Percent \\
\hline Show stance/position & 12 & 3 & 15 & 80.00 \\
Acknowledgements/gratitude & 2 & 2 & 4 & 50.00 \\
Announce topic & 2 & 0 & 2 & 100.00 \\
Offer an explanation & 10 & 0 & 10 & 100.00 \\
Make generalization/offer speculation & 2 & 0 & 2 & 100.00 \\
Set the scene & 2 & 0 & 2 & 100.00 \\
Present an argument & 4 & 1 & 5 & 80.00 \\
closure & 2 & 0 & 2 & 100.00 \\
Call for action & 2 & 1 & 3 & 66.67 \\
Total & 38 & 7 & 45 & 84.44 \\
\hline
\end{tabular}

Table 2. Length of each part.

\begin{tabular}{|c|c|c|c|c|c|c|c|c|}
\hline & introduction & $\%$ & body & $\%$ & conclusion & $\%$ & $\begin{array}{c}\text { Full } \\
\text { discourse }\end{array}$ & $\%$ \\
\hline $\begin{array}{l}\text { Average words } \\
\text { (SD) }\end{array}$ & $\begin{array}{c}134.5 \\
(131.1)\end{array}$ & 6.76 & $\begin{array}{c}1680.6 \\
(1004.8)\end{array}$ & 84.43 & $\begin{array}{c}171.8 \\
(130.1)\end{array}$ & 8.63 & $\begin{array}{c}1990.4 \\
(1120.2)\end{array}$ & 100 \\
\hline
\end{tabular}


author identified 264 moves and the occurrence of all the types of move is shown in Table 3. We can see that topic development (102) and speaker presentation (82) are the two most frequently occurred moves in the talks. In terms of distribution in the three parts of a talk the data indicates that the introduction parts often contain moves like topic introduction (13) and speaker presentation (12), what is interesting here that although greeting is a commonly used strategy in delivering presentation to draw attention from the audience. In TED talks the presenters rarely employed listener orientation move (3) and especially the greet audience step (1). Topic development (94) and speaker presentation (66) are most frequently used in the body part, and concluding message and acknowledgement are mostly found in the conclusion part (see Table 3 ).

In order to classify what are the essential move or optional moves to TED talks in education the author counted the occurrence of these move in different talks. Only when the occurrence of certain moves in the same part covered more than $60 \%$ of the total talks (Kanoksilapatham, 2007), the move can be recognized as an essential move in this part. Table 4 illustrate that Topic introduction and

Table 3. Moves and steps in each part.

\begin{tabular}{|c|c|c|c|c|}
\hline \multirow{2}{*}{ Move steps } & \multicolumn{3}{|c|}{ Total number of occurrences $(n=264)$} & \multirow{2}{*}{ Total (\%) } \\
\hline & Introduction & Body & Conclusion & \\
\hline Listener orientation & 3 & 0 & 0 & 3 \\
\hline Greet audience & 1 & 0 & 0 & $1(33 \%)$ \\
\hline Engage in meta-level discussion & 2 & 0 & 0 & $2(66 \%)$ \\
\hline Topic introduction & 13 & 6 & 0 & 19 \\
\hline Set the scene & 7 & 3 & 0 & $10(53 \%)$ \\
\hline Announce topic & 6 & 3 & 0 & $9(47 \%)$ \\
\hline Outline structure & 0 & 0 & 0 & $0(0 \%)$ \\
\hline Speaker presentation & 12 & 66 & 4 & 82 \\
\hline Introduce oneself & 5 & 1 & 0 & $6(7 \%)$ \\
\hline Establish authority & 3 & 3 & 0 & $6(7 \%)$ \\
\hline Show stance/position & 4 & 62 & 4 & $70(86 \%)$ \\
\hline Topic development & 0 & 94 & 8 & 102 \\
\hline Present an argument & 0 & 12 & 3 & $15(15 \%)$ \\
\hline Describe a process/series of events & 0 & 5 & 0 & $5(5 \%)$ \\
\hline Offer an explanation & 0 & 77 & 5 & $82(80 \%)$ \\
\hline Closure & 0 & 0 & 6 & 6 \\
\hline Concluding messages & 0 & 6 & 16 & 22 \\
\hline Call for action & 0 & 5 & 7 & $12(55 \%)$ \\
\hline $\begin{array}{l}\text { Make generalization/ } \\
\text { offer speculation }\end{array}$ & 0 & 1 & 9 & $10(45 \%)$ \\
\hline Acknowledgements/gratitude & 2 & 4 & 11 & 17 \\
\hline
\end{tabular}


Table 4. Total moves and steps in each part.

\begin{tabular}{|c|c|c|c|}
\hline \multirow{2}{*}{ Move steps } & \multicolumn{3}{|c|}{ Numbers of talks contain this move $(n=12)$} \\
\hline & Introduction (\%) & Body (\%) & Conclusion (\%) \\
\hline Listener orientation & $2(16.67)$ & $0(0)$ & $0(0)$ \\
\hline Greet audience & $1(8.33)$ & $0(0)$ & $0(0)$ \\
\hline Engage in meta-level discussion & $2(16.67)$ & $0(0)$ & $0(0)$ \\
\hline Topic introduction & $8(66.67)$ & $3(25)$ & $0(0)$ \\
\hline Set the scene & $7(58.33)$ & $3(25)$ & $0(0)$ \\
\hline Announce topic & $6(50)$ & $3(25)$ & $0(0)$ \\
\hline Outline structure & $0(0)$ & $0(0)$ & $0(0)$ \\
\hline Speaker presentation & $8(66.67)$ & $12(100)$ & $4(33.33)$ \\
\hline Introduce oneself & $5(41.67)$ & $1(8.33)$ & $0(0)$ \\
\hline Establish authority & $3(25)$ & $3(25)$ & $0(0)$ \\
\hline Show stance/position & $2(16.67)$ & $12(100)$ & $4(33.33)$ \\
\hline Topic development & $0(0)$ & $12(100)$ & $6(50)$ \\
\hline Present an argument & $0(0)$ & $5(41.67)$ & $2(16.67)$ \\
\hline Describe a process/series of events & $0(0)$ & $3(25)$ & $0(0)$ \\
\hline Offer an explanation & $0(0)$ & $12(100)$ & $5(41.67)$ \\
\hline Closure & $0(0)$ & $0(0)$ & $6(50)$ \\
\hline Concluding messages & $0(0)$ & $3(25)$ & $10(83.33)$ \\
\hline Call for action & $0(0)$ & $3(25)$ & $6(50)$ \\
\hline $\begin{array}{l}\text { Make generalization/ } \\
\text { offer speculation }\end{array}$ & $0(0)$ & $1(8.33)$ & $9(75)$ \\
\hline Acknowledgements/gratitude & $2(16.67)$ & $3(25)$ & $10(83.33)$ \\
\hline
\end{tabular}

Speaker presentation moves were identified in the introduction of 8 out of 12 talks $(66.67 \%)$ therefore should be considered as essential moves in the introduction part. Other moves like listener orientation and acknowledgement moves (16.67\%) are less frequently used optional moves in this part. As for all the 12 talks contained Speaker presentation and Topic development move in the body part these two moves were classified as obligatory moves in the body part. The appearance of moves like Topic Introduction, Concluding Messages, and Acknowledgements/gratitude were only about $25 \%$ and should viewed as optional. The conclusion part included two essential moves namely Concluding Messages Acknowledgements/gratitude for them are identified in the conclusion of 10 out of 12 talks (83.33\%), what should be noticed here is although the frequency of closure and topic development moves were less than $60 \%$ talks $50 \%$ of occurrence also indicated that these moves were typical in the conclusion of educational TED talks (Table 5).

3) Features of move model in TED education talks

Compared with other formal oral presentations move analysis of TED education 
Table 5. Essential moves and steps in each part.

\begin{tabular}{cccc}
\hline & Introduction & Body & Conclusion \\
\hline \multirow{2}{*}{ Essential } & Topic introduction & Speaker presentation & Concluding messages \\
& Speaker presentation & Topic development & Acknowledgements/gratitude \\
& & Topic introduction & \\
Non-essential & Acknowledgements/ & Concluding messages & Speaker presentation \\
& gratitude & Acknowledgements/ & Topic development \\
& & gratitude & Closure \\
\hline
\end{tabular}

talks revealed some unique characteristic in this specific genre.

TED conventions and personal flexibility

In the instruction of public speech, greeting the audience is viewed as one the most commonly used strategy in the introduction part, and serves the purpose of signaling the beginning of a presentation, asking for attention from the audience, and calm down the noise (Lucas, 2010). Through move analysis about the 12 education talks in TED the author found that only 1 out of 12 speakers employed this strategy in his speech, and similar result can be found in Chang and Huang's study in 2015 that only 2 speakers in their 58 selected talks greeted the audience at the beginning of their presentations. It seemed that although greeting the audience is a useful and highly recommended step in general oral presentation, in the specific context of TED most presenters followed the unique feature of this genre. This finding suggests the novice presenters to analyze the genre and be aware of the acceptable convention before preparing for the speech.

By analyzing the moves of 12 talks, the frequency of different moves and the obligator move structure of TED education talks indicated that the employment of move in a presentation is flexible and mainly based on the communicative goals of the presenters especially in the introduction and body parts.

The basic move structure of TED education talks

Besides the personal flexibility of move choice, this paper also identified a basic move structure consisted of the move repeated occurring in the same section and in more than $60 \%$ of the talks. The obligatory moves found in education TED talks mainly consistent with the common structure of oral presentation. Compared with the structure identified by Chang and Huang (2015), some genre specific features in education talks can be found. In the introduction part Chang and his colleagues only found one essential move in the 58 talks, in the current study the author found that most of the speakers in education talks also tended to establish their authority and present their position at the beginning of talks. In the body section in the specific genre Speaker Presentation was obligatory compared with previous study. The move of closure didn't employ by many speakers in the conclusion, for some of the speakers directly used call for action and make generalization to be signal of going to end the presentation. As can be seen in Table 5, in the body part present argument, and offer explanation steps in the same move of topic development usually occurred together to provide information before the presenter showing his or her stance. 


\section{Discussion and Implication}

The current research focuses on the specific discipline of education in TED talks, compared with previous studies the author identifies more essential moves in the samples and provides a clearer move structure of education TED presentations, partly proves the assumption that move structure is a more discipline-specific model. In this study the author finds that on the one hand TED talks share some common features with other forms of public speech, especially in the conclusion part that contains relatively fixed moves like concluding massage and acknowledgment. Besides, TED talks demonstrate more unique conventions, for example rarely occurred greeting the audience step in the introduction part and the appearance of acknowledgement move throughout the whole talk. The study also reveals that the special environment of presenting innovative ideas in the 18 minutes rather than deliver a 3 minutes speech which is usually adopted speech practice in the oral skill course, TED presenters can devote more time to set the scene and establish their authority, in the body parts the speakers have more chances to elaborate their stance with clear explanation or description of a process, and often use argument to stimulate thinking or reflection from the audience. The much richer content and moves in TED talks provide the learners with abundant examples of how to deliver a credible, thoughtful, and inspiring speech in front of a large group of audiences. The analysis of move pattern in educational TED talks illustrates that the move structure is strongly affected by the purpose, the convention of the conference and personal style.

The author explores the move structure of 12 educational TED talks aiming to determine the pedagogical potential of TED talks as useful materials for enhancing students' oral presentation skills. This corpus-based move analysis of educational TED talks determines genre specific move structure of TED talks which can help the beginners to get a basic understanding about the education genre in TED talks. The move structure inducted from analysis of expert presenters of TED can set a good example for the novice speakers and facilitate them in preparing a speech in similar conditions.

The move analysis can help the students to be aware of the regularity as well as the variation in exact genre of TED talks by using the provided criteria of moves in TED talks, the instructors can guide the students to analyze and evaluate TED talks by themselves.

\section{Conflicts of Interest}

The authors declare no conflicts of interest regarding the publication of this paper.

\section{References}

Biber, D., Connor, U., \& Upton, T. A. (2007). Discourse on the Move: Using Corpus Analysis to Describe Discourse Structure. Amsterdam: John Benjamins. 
https://doi.org/10.1075/scl.28

Biber, D., Conrad, S., Reppen, R., Byrd, P., \& Helt, M. (2002). Speaking and Writing in the University: A Multidimensional Comparison. TESOL Quarterly, 36, 9-48. https://doi.org/10.2307/3588359

Bunch, G. C. (2009). "Going Up There”: Challenges and Opportunities for Language Minority Students during a Mainstream Classroom Speech Event. Linguistics and Education, 20, 81-108. https://doi.org/10.1016/j.linged.2009.04.001

Chang, Y.-J., \& Huang, H.-T. (2015). Exploring TED Talks as a Pedagogical Resource for Oral Presentations: A Corpus-Based Move Analysis. English Teaching \& Learning, 39, 29-62.

Chou, M. (2011). The Influence of Learner Strategies on Oral Presentations: A Comparison between Group and Individual Performance. English for Specific Purposes, 30, 272-285. https://doi.org/10.1016/j.esp.2011.04.003

Connor, U., Upton, T. A., \& Kanoksilapatham, B. (2007). Introduction to Move Analysis. In D. Biber, U. Connor, \& T. A. Upton (Eds.), Discourse on the Move: Using Corpus Analysis to Describe Discourse Structure (pp. 23-41). Amsterdam: John Benjamins.

DaVia Rubenstein, L. (2012). Using TED Talks to Inspire Thoughtful Practice. The Teacher Educator, 47, 261-267. https://doi.org/10.1080/08878730.2012.713303

De Grez, L., Valcke, M., \& Roozen, I. (2009). The Impact of an Innovative Instructional Intervention on the Acquisition of Oral Presentation Skills in Higher Education. Computers \& Education, 53, 112-120. https://doi.org/10.1016/j.compedu.2009.01.005

Evans, S. (2013). "Just Wanna Give You Guys a Bit of an Update”: Insider Perspectives on Business Presentations in Hong Kong. English for Specific Purposes, 32, 195-207. https://doi.org/10.1016/j.esp.2013.05.003

Kanoksilapatham, B. (2007). Rhetorical Moves in Biochemistry Research Articles. In D. Biber, U. Connor, \& T. A. Upton (Eds.), Discourse on the Move: Using Corpus Analysis to Describe Discourse Structure. Amsterdam: John Benjamins. https://doi.org/10.1075/scl.28.06kan

Lucas, S. E. (2010). The Art of Public Speaking (10th ed.). Beijing: Foreign Language Teaching and Research Press.

Swales, J. M. (1990). Genre Analysis: English in Academic and Research Settings. Cambridge: Cambridge University Press.

Swales, J. M. (2004). Research Genres: Exploration and Applications. New York: Cambridge University Press. https://doi.org/10.1017/CBO9781139524827

Takaesu, A. (2013). TED Talks as an Extensive Listening Resource for EAP Students. Language Education in Asia, 4, 150-162. https://doi.org/10.5746/LEiA/13/V4/I2/A05/Takaesu

Tardy, C. M. (2011). Genre Analysis. In K. Hyland, \& B. Paltridge (Eds.), The Continuum Companion to Discourse Analysis (pp. 54-68). London: Continuum.

Thompson, S. (1994). Frameworks and Contexts: A Genre-Based Approach to Analyzing Lecture Introductions. English for Specific Purposes, 13, 171-186. https://doi.org/10.1016/0889-4906(94)90014-0

Upton, T. A., \& Cohen, M. A. (2009). An Approach to Corpus-Based Discourse Analysis: The Move Analysis as Example. Discourse Studies, 11, 585-605. https://doi.org/10.1177/1461445609341006 